\title{
TERMINOLOGIA - RECONSTRUÇ̃̃O HISTÓRICA DOS PRINCIPAIS PARADIGMAS EPISTEMOLÓGICOS DA CIÊNCIA TERMINOLÓGICA
}

\author{
Maria de Lourdes Rossi Remenche ${ }^{1}$
}

\begin{abstract}
RESUMO: Este artigo tem como objetivo analisar os modelos teóricos da Terminologia. Para tanto faz uma incursão pelas origens da Terminologia numa leitura histórica do seu desenvolvimento e sua associação à consciência dos cientistas sobre a importância das nomenclaturas científicas para a fixação e circulação do saber científico e técnico. O nascimento da Terminologia moderna advém dessa necessidade de normalizar, conceitual e denominativamente, os campos das ciências. Nesse sentido, o presente estudo faz uma retomada da Teoria Geral da Terminologia (TGT) para chegar a uma análise da Teoria Comunicativa da Terminologia (TCT), que estabelece fundamentos mais amplos e flexiveis para a Terminologia, instrumentalizando e fortalecendo-a para o desenvolvimento de seu objetivo - estudar e descrever, completa e adequadamente, os objetos terminológicos, abrindo possibilidades para o tratamento de realidades distintas. Para essa análise, baseamo-nos em Barbosa (1996), Cabré (1993; 1998; 1999), Krieger (2001), Rondeau (1984) e Wüster (1998).
\end{abstract}

PALAVRAS-CHAVE: Linguagem de especialidade; Terminologia; Teoria Geral da Terminologia; Teoria Comunicativa da Terminologia.

\footnotetext{
Doutora em Linguística e Semiótica pela USP.
} 
ABSTRACT: This paper aims to analyze the theoretical patterns of Terminology. It covers an incursion of Terminology origins with a historical reading of its development and its association towards scientists' awareness about the importance of scientific denomination to the spread and fixation of the technical and scientific knowledge. The birth of modern Terminology appears from the necessity to rule, through concepts and denominations, the fields of science. This paper also gives a general view of General Theory of Terminology (GTT) to reach to an analysis of the Communicative Theory of Terminology (CTT) which establishes broader and more flexible basis for Terminology, strengthening its development and its aim which are to study, to describe, fully and properly, the terminological objects, leading new possibilities of treating distinct realities. For this analysis, we based on Barbosa (1996), Cabré (1993, 1998, 1999), Kriger (2001), Rondeau (1984), Wüster (1998)

KEYWORDS: Language of specialties; Terminology; General Theory of Terminology; Communicative Theory of Terminology.

\section{Introdução}

A linguagem é um emaranhado e complexo feixe de relações sócioverbais, produto da sociedade. Observamos o mundo a partir de esquemas culturais de representação mental em que fatores como posição e meio social, profissão, idade, sexo do locutor/interlocutor interferem na escolha do falante e, consequentemente, influenciam na variação linguística. Soma-se a isso a influência de elementos externos, discutida por Saussure (1994), em que a história de uma língua, uma raça ou civilização e as relações da língua com as diversas instituições podem modificar os elementos internos da língua, assim como os fatores externos. Desse modo, o desenvolvimento científico caracteriza-se como um elemento externo da língua.

A diferenciação entre subgrupos sociais faz com que a linguagem seja um sistema complexo e heterogêneo de subsistemas

TradTerm, 16, 2010, p. 343-364 
interrelacionados que podem ser descritos em diferentes níveis como, por exemplo, o morfológico, o sintático, o lexical etc. O nivel lexical é uma forma de registrar e transmitir o conhecimento criado e acumulado através dos tempos, e é marcado pela conceitualização da realidade, que se cristaliza a partir de um símbolo verbal, ou seja, uma representação linguística, caracterizando, dessa forma, o processo cognitivo de formação do léxico. São ações sucessivas de cognição da realidade e ordenação dos dados sensoriais da experiência, materializadas em signos linguísticos.

Esse signo verbal é fundamental para a formação do conceito que, para Vygotsky (1977), é uma parte ativa do processo intelectual que visa a servir à comunicação, ao entendimento e à solução de problemas. O conceito, portanto, é dinâmico e pode ser continuamente revisto e reformulado; consequentemente, os termos ou palavras a que se referem também podem ser revistos, seja em sua face de significante, seja em sua face de significado.

O sistema linguístico apresenta variações em relação às características das situações comunicativas que requerem uma adequação discursiva, determinadas pela especialização dos elementos constituintes do processo de comunicação.

A humanidade desenvolveu a ciência e as técnicas gradativamente, num movimento que exigiu a ampliação do repertório linguístico, responsável por documentar as criações e os novos conceitos. Essa linguagem especializada é frequentemente chamada de jargão, denominação em que subjazem aspectos pejorativos do vocabulário especializado e que gera alguns desencontros com a área da Terminologia - disciplina linguística consagrada ao estudo científico dos conceitos e dos termos empregados nas línguas de especialidade (Pavel \& Nolet, 2002).

Para revisitarmos os principais paradigmas epistemológicos da ciência terminológica, faremos uma breve retomada das origens da Terminologia, dos princípios gerais da Teoria Geral da Terminologia (TGT) e da Teoria Comunicativa da Terminologia (TCT) a fim de refletirmos sobre os movimentos de complementaridade e ampliação dos estudos na área. 


\title{
2. Origens da Terminologia - Uma Leitura Histórica
}

As nomenclaturas técnico-científicas são importantes para a fixação e circulação do saber científico e técnico. Enquanto componente lexical das comunicações especializadas, essas nomenclaturas fazem parte da história da humanidade. Rondeau comenta isso quando afirma que:

\begin{abstract}
A terminologia não é um fenômeno recente. Com efeito, tão longe quanto se remonte a história do homem, desde que se manifesta a linguagem, nos encontramos em presença de linguas de especialidade, é assim que se encontra a terminologia dos filósofos gregos, a língua de negócios dos comerciantes cretas, os vocábulos especializados da arte militar etc. (Rondeau, 1984:01 - tradução nossa)
\end{abstract}

Como ciência da linguagem, a Terminologia se dedica à observação e estudo do léxico e das relações de significações dos signos terminológicos. Almeida (2003) destaca que a função do sistema lexical de uma língua natural é nomear o mundo; isso inclui as ciências e as tecnologias, portanto, não é possivel expressar o mundo, de forma completa, sem terminologias.

Já no século IX, o físico Rhazés (865-925) relacionou o nome de órgãos do corpo humano e doenças, em cinco línguas, no Liber Continentis (Livro Abrangente) (Sidarus, 1990). Platão (427-347 a. C.), em Crátilo, fez discussões em torno das palavras e da pertinência dos nomes, realizando as primeiras reflexões filosóficas (Platão, 2001). Cabré (1993) comenta que a prática terminológica teve início com os trabalhos científicos de Lavoisier e Berthold no domínio da química, Linné na botânica e zoologia no século XVIII, que buscaram relacionar/associar as denominações aos conceitos científicos. Finalmente, a consolidação da Terminologia deve muito a naturalistas como Karl Von Lineu (1707-1778), que propôs um sistema universal de nomenclatura binominal e dotou a botânica e a zoologia de regras precisas de criação de nomes científicos para designarem espécies da flora e da fauna do mundo todo, independente do idioma falado pelo cientista.

O desenvolvimento progressivo das ciências favoreceu a busca, cada vez mais acentuada, do entendimento e descrição

TradTerm, 16, 2010, p. 343-364 
das regras de formação dos termos dos domínios de especialidade. Isso é expresso nos colóquios e/ou congressos internacionais de botânicos (1867), zoólogos (1889) e químicos (1892), que aconteceram no final do século XIX. Benveniste (1989) salienta a dimensão cognitiva das terminologias nas especialidades que advêm do avanço do conhecimento, quando afirma que:

\begin{abstract}
A constituição de uma terminologia própria marca, em toda ciência, o advento ou o desenvolvimento de uma conceituação nova, assinalando, assim, um momento decisivo de sua história (...). Uma ciência só começa a existir ou consegue se impor na medida em que faz existir ou consegue se impor na medida em que faz existir e em que impõe seus conceitos, através de sua denominação. Ela não tem outro meio de estabelecer sua legitimidade senão por especificar seu objeto denominando-o, podendo este constituir uma ordem de fenômenos, um domínio novo ou um modo novo de relação entre certos dados (...). Denominar, isto é, criar um conceito, é, ao mesmo tempo, a primeira e última. (Benveniste, 1989:252)
\end{abstract}

Com o progresso das ciências e das técnicas e o acelerado desenvolvimento das tecnologias na primeira metade do século $\mathrm{XX}$, acentuou-se a necessidade de denominar novos conceitos e, sobretudo, harmonizar as novas denominações realizadas nos trabalhos técnicos. O desenvolvimento da Terminologia ocorreu na cultura da sociedade rural e da cultura industrial do século XIX e início do XX, passando para a cultura pós-industrial da segunda metade do século XX em que o papel das terminologias na representação, padronização e discriminação linguística \do conhecimento começou a se fortalecer.

As mudanças políticas e socioeconômicas acabaram repercutindo no nível vocabular, pois a cada atividade, produto, lei etc. surgiam termos equivalentes, levando a uma ampliação do universo lexical e dos conjuntos terminológicos.

Três escolas estudaram a Terminologia: a Escola Soviéti$c a$, que teve como representante maior Dimitri S. Lotte ${ }^{2}$, privile-

2 Para Rondeau (1984), D. S. Lotte (1889-1950) foi o pai da Terminologia. 
giando o aspecto sistêmico dos conceitos; a Escola Tcheca ou Escola de Praga, representada por L. Drodz, de base linguística; e a Escola de Viena ou Austríaca ${ }^{3}$, que teve como marco fundador a tese doutoral de Eugen Wüster (1899-1977). Esse trabalho marcou o surgimento dessa disciplina científica que se constituiu numa ciência social. A Escola de Viena atribuiu grande importância à dimensão conceitual e propagou a ideia de univocidade, fundamentada nos pressupostos da monossemia terminológica, da exclusividade designativa, bem como da monorreferencialidade.

\section{Teoria Geral da Terminologia (TGT) - o nascimento}

A Terminologia moderna surgiu da necessidade de cientistas e técnicos de normalizar conceitual e denominativamente seus campos de estudo. Nesse contexto, o austríaco Eugen Wüster (1898-1977), formado em Engenharia Elétrica pela Universidade de Berlim, perseguindo o ideal de univocidade da língua de especialidade, desenvolveu a chamada Teoria Geral da Terminologia (TGT) com a publicação, em 1931, de sua tese de doutorado intitulada Internationale Sprachnormung in der Technik, besonders in der Elektrotecknik (A normalização internacional da terminologia técnica, com ênfase especial na eletrotécnica), pela Universidade Técnica de Stutgart, na Alemanha. Nesse trabalho, ele discutiu o tema da precisão conceitual na linguagem, explicitando os motivos para a sistematização dos métodos do trabalho. Para tanto, constituiu princípios e diretrizes metodológicas para o tratamento dos dados terminológicos, e produziu, posteriormente, o dicionário The Machine Tool (1968), em que esboça as linhas gerais da TGT.

Wüster construiu o pensamento teórico em torno do termo terminologia, definindo-o como sistema de conceitos próprios a um domínio especializado e de suas denominações, ou seja, um conjunto de termos com suas significações, em que, numa

A Escola de Viena trabalhou com a perspectiva cognitiva da Terminologia ao compreender o léxico especializado como representação de conhecimentos produzidos pela ciência.

TradTerm, 16, 2010, p. 343-364 
dada língua, se constitui como domínio especializado, ou, se quiser, lexicologia especializada desse domínio, a partir de uma visão sincrônica e sem preocupação com a morfologia e a sintaxe.

A divulgação da versão russa da tese de Wüster despertou interesse pela área nos domínios especializados e influenciou a criação do Comitê Técnico 37 Terminologia (TC37) da ISA (International Standardization Association) vinculada à Federação International das Associações Nacionais de Normalizadores, a precursora da atual ISO (International tandardization Organization) (Cabré, 1993; 1996). O TC37 prevê o cumprimento das condições básicas da denominação, estabelecendo prioridades entre eles, além de objetivar a economia linguística, pois a exatidão da expressão relaciona-se à menor agilidade da palavra. Em torno dessa concepção clássica e de cunho normativo da terminologia, desenvolveu-se a Escola de Viena, que compreendia o léxico especializado como representação de conhecimentos produzidos pela ciência, privilegiando, dessa forma, a lingua universal, a univocidade comunicacional e a perspectiva cognitiva da linguagem.

O Infoterm - Instituto Austríaco de Normalização - e o Instituto Internacional de Investigação Terminológica, constituído por terminólogos, linguistas e especialistas de documentação, investiram no desenvolvimento teórico mais sistemático e coerente já realizado sobre os termos (Cabré, 1996).

Enquanto o trabalho dos linguistas tem como base o conteúdo das palavras e sua evolução espontânea, o trabalho do terminólogo se fundamenta nos conceitos - e sua representação por termos, símbolos, e outros signos linguísticos, ponto de partida para a denominação e procedimento de busca da terminologia - e na formação consciente da língua. Inicialmente, a Terminologia foi concebida como disciplina autônoma, porém, com interfaces com as ciências das coisas e com outras disciplinas como a Linguística, a Lógica, a Ontologia e a Ciência da Informação, imbricada com diversas áreas de saber, como a Informática, a Física, a Economia etc., delineando, dessa forma, seu caráter multidisciplinar e se constituindo como área inter e transdisciplinar. Wüster estabelecia uma relação entre a Terminolo- 
gia, os domínios da vida e sua utilidade ${ }^{4}$, vinculando as características dos termos técnico-científicos à função de representação e de transmissão dos conhecimentos especializados em todos os campos do saber científico e tecnológico.

Wüster (1998) considerava a língua científica e técnica como a língua de uso oposta, então, à língua literária; acreditava, ademais, na formação consciente da língua. O termo/denominação, segundo o autor, é o símbolo linguístico correspondente ao conceito num contexto técnico-científico. Esse pesquisador buscou eliminar a ambiguidade da linguagem técnica e transformá-la num instrumento eficaz. Para tanto propôs a normalização, método que se tornou imprescindivel à tecnologia. De acordo com Felber (1996), essa foi a gênese da normalização da terminologia e da organização consciente da língua.

Uma das faces da Terminologia estuda os princípios teóricos e metodológicos de coleta, classificação, criação e normalização dos termos. O trabalho com as unidades significativas das linguagens de especialidade envolve, entre outros objetivos, a produção e divulgação de glossários, vocabulários, dicionários e banco de dados que contêm a terminologia específica do domínio, ou seja, o conjunto de termos de uma área especializada.

As diferentes visões da língua são bem aparentes na sua representação em dicionários de Terminologia; elas envolvem a definição adequada do conceito e a entrada em ordem sistemática. Wüster (1998) apresenta, de um lado, os sistemas de conceitos especiais - em que constam os sistemas de conceitos lógicos, os sistemas partitivos e os sistemas de conceitos mistos. De outro, apresentam-se os sistemas temáticos, que ocorrem em séries verticais ou horizontais e em combinações de temas, além dos sistemas de signos de classificação/notações, que podem ser grupos de cifras, letras, grupos mistos de cifras e letras e, também, palavras ou grupos de palavras.

O trabalho de Wüster buscou a difusão de terminologias normalizadas com o objetivo de contribuir para uma comunica-

“(...) A Terminologia vai além da Linguística por reunir conhecimentos linguísticos em todos os domínios da vida e torná-los úteis a todos os dominios da vida. (Wüster apud Rondeau \& Felberg, 1981)

TradTerm, 16, 2010, p. 343-364 
ção eficiente e rápida, o que acabou por configurar a TGT como uma terminologia representativa e prescritiva, visto que denominava e etiquetava informações. Sob tal enfoque, a terminologia expressa conceitos e não significados.

A concepção wüsteriana é fundamentada num modelo positivista de ciência, em que os conceitos científicos são estáveis, pragmáticos e universais e, ainda, a língua científica é um lugar homogêneo e transparente, que tem por função expressar verdades científicas. Assim, ocorre um controle mais eficiente das terminologias para que a comunicação seja, de fato, eficaz e inequivoca.

A contribuição de Wüster para a constituição dos princípios e desenvolvimento dos estudos teóricos e aplicados da área da Terminologia é inegável. Cabré (1999) comenta que a TGT é coerente e sistemática, suficiente para os trabalhos terminológicos de orientação onomasiológica e de finalidade estandardizada. Para a comunicação real, no entanto, essa teoria emprega alguns princípios que se mostram inconsistentes, visto que essa comunicação é apenas uma das formas da comunicação real, ou seja, ela não ampliou as possibilidades explicativas, tornandose apenas orientações metodológicas para a produção terminográfica, alicerçada numa visão idealizada e normalizadora do componente lexical temático das línguas.

Se considerarmos o contexto do surgimento da teoria wüsteriana, entenderemos que suas deficiências decorrem de uma proposta que nasceu da necessidade, de técnicos e de cientistas, de normalizar denominativa e conceitualmente suas disciplinas a fim de garantir a comunicação profissional e a transferência de conhecimento, num momento em que se buscava uma língua universal que permitisse superar os obstáculos que a linguagem comum causava.

Com o surgimento de novas demandas informativas e comunicacionais, a partir dos anos 90, alguns especialistas em terminologia articularam uma revisão crítica dos fundamentos teóricos epistemológicos originais da TGT, alegando que a teoria de Wüster era restritiva e não possibilitava a descrição, de forma satisfatória, do léxico especializado. Cabré (1998), nesse sentido, comenta que a teoria wüsteriana: 


\begin{abstract}
limita o objeto às unidades unívocas normalizadoras próprias dos âmbitos científico-técnicos, reduz a atividade terminológica à recolha de conceitos e termos para a normalização (fixação de noções e denominações normatizadas) dos termos, circunscreve os âmbitos especializados à ciência e à técnica e limita seus objetivos para assegurar a univocidade da comunicação profissional, fundamental no plano internacional. (Cabré, 1998:02)
\end{abstract}

Essas proposições abalam a ideia de univocidade, ancorada nos pressupostos de exclusividade designativa, monossemia terminológica e monorreferencialidade pregados pela escola de Viena. Soma-se a isso o apagamento da pluralidade tipológica dos trabalhos que advém das diferentes necessidades terminológicas, a dinâmica constante dos dominios especializados e a diversidade da terminologia, determinada pelas características pragmáticas da comunicação, inerentes ao léxico das linguagens especializadas. As restrições elencadas evidenciaram, enfim, um reducionismo diante do funcionamento da linguagem e contribuiram para que a TGT fosse criticada e vista como uma teoria insuficiente.

A TGT também não explora a dimensão social dos termos, pois os concebe, unicamente, como elementos denominativos (dimensão representacional) e limita seu uso à comunicação entre especialistas e profissionais (dimensão comunicativa). Em virtude disso, Rey (1979) argumenta que é na reflexão sobre o nome e a denominação, base da terminologia, que encontramos toda a reflexão sobre a linguagem e o sentido. Ou seja, a produção terminológica não é compreendida apenas a partir do ponto de vista descritivo, mas vai além, extrapola o constructo ideal e homogêneo de uma comunicação, sem polissemia e ambiguidades conceituais restrita ao âmbito dos especialistas, e passa a ser compreendida como uma questão de linguagem.

\title{
4. Um novo percurso: da TGT à Teoria Comunicativa da Terminologia (TCT)
}

A constituição multifacetada da TGT ocasionou movimentos diferentes em relação ao sistema denominativo das ciências

TRADTERm, 16, 2010, p. 343-364 
e das técnicas. Isso favoreceu o surgimento de teorias e metodologias que questionavam a natureza constitutiva e a funcionalidade dos léxicos terminológicos, provocando uma reavaliação crítica dos fundamentos teóricos e epistemológicos da Terminologia, que se baseavam numa visão idealizada, reducionista e normalizadora do componente lexical temático das línguas. Tal renovação não invalida a teoria wüsteriana, mas amplia seu alcance sem distinguir as situações de aplicação.

Pesquisadores como Rey, em sua obra La Terminologie: noms et notions (1979), Sager (1990) Gaudin (1991; 1995), Temermann (1997) e Cabré $(1992 ; 1998)$, apresentaram discordância em relação aos postulados wüsterianos. Cabré (1999), por exemplo, questiona a TGT quando afirma que, à luz das necessidades atuais, a teoria de Wüster não descreve satisfatoriamente os termos porque não dá conta de aspectos como: a multiciplinariedade de aborgagens das UTs (denominativa, cognitiva e funcional); a poliedricidade de todas e de cada uma de suas unidades, além de sua dupla função na realidade do discurso especializado (representativa e comunicativa); a distinção entre seu valor descritivo e o prescritivo, de acordo com as situações comunicativas; a variação conceitual inerente a toda unidade de conhecimento, ligada à cultura geral e científica, determinante da visão de mundo; a dependência linguística das unidades terminológicas, realizadas nas línguas particulares e, por fim, a variação denominativa, característica ao discurso e à comunicação, em função dos aspectos pragmáticos.

Essas deficiências são decorrentes do caráter metodológico, da natureza prescritiva e normalizadora da TGT, que não têm preocupação com os modos de funcionamento dos léxicos terminológicos. Sua insuficiência, de acordo com Cabré et al (1998) ainda, deve-se a questões como o método de análise lógica da realidade - o logicismo - que é a forma científica de descrever o mundo. Isso se evidencia, por exemplo, na descrição dos tipos de relação entre os conceitos, que aparecem denominados por um modelo de organização do conhecimento do caráter hierárquico e binário. As relações que não se encaixam nesse modelo são apenas apontadas e não são suficientemente descritas. Embora Cabré (1999) destaque que os princípios da TGT eram 
suficientes para as finalidades a que se propunha, a teoria apresentava deficiências por não considerar a relação próxima entre terminologia e língua natural e, consequentemente, os aspectos envolvidos.

Outro ponto que favoreceu as críticas foi o fato de a análise do conhecimento especializado ser aplicada, da mesma forma, a contextos geográficos e a realidades socioeconômicas, culturais e linguísticas completamente distintas a partir do princípio do Universalismo, em que o método de análise do conhecimento especializado tem pretensões universais e é explicitado, por exemplo, nas normas sobre princípios e métodos internacionais aprovadas pela ISO. Em virtude disso, muitos estudiosos entendem a normatização institucionalizada como uma espécie de ditadura do modo conceitual europeu para entender o conhecimento e as ciências.

Embora a TGT reconheça o fato de que os conceitos evoluem, seu modelo de representação do conhecimento tem caráter marcadamente estático, numa perspectiva estritamente sincrônica, não propiciando, em sua análise da realidade, a integração de elementos que deem conta da dinamicidade e evolução do conhecimento especializado, bem como de suas denominações. Soma-se a isso o fato de a aplicação da TGT, em âmbito original, estar ligada à técnica em geral, à mecânica e, em particular, à engenharia.

A TGT apresentou, portanto, redução na sua capacidade de descrição do modelo, com dificuldade para dar conta das distintas realidades. Tal reducionismo diz respeito ao enfoque do tratamento de muitos aspectos da terminologia, tanto na teoria como em sua aplicação, sem justificativa empírica, e ignorando os dados da realidade da comunicação especializada.

Dentre outros aspectos que evidenciam o caráter reducionista dessa proposta, Cabré (1999) destaca: o fato de os objetivos atribuídos à matéria se limitarem à busca pela univocidade da comunicação profissional, contrariando a complexidade interdisciplinar e negando a variação formal e conceitual como aspectos importantes para a investigação; o trabalho, de forma global, com a unidade terminológica, separando o conceito (supostamente, de uma língua universal) do significado (ligado às 
línguas particulares); a redução das unidades terminológicas (UTs) à condição denominativa, sem observar os elementos linguísticos constituintes e a estrutura morfológica interna do termo; a não atenção aos aspectos sintáticos, comunicativos e discursivos das UTs; o silêncio em relação à variação formal e conceitual das unidades especializadas, além da rigidez no trabalho com a UT não permitir a análise da poliedricidade do termo.

A terminologia proposta pela TGT, ainda de acordo com Cabré (1998), parece refletir um idealismo, em que os conceitos são entes preexistentes às expressões, criados por consenso e que etiquetam/nomeiam, por meio dos termos, realidades com valor supralinguístico e supracultural. Dessa forma, os termos são considerados rótulos, com os quais denominamos os resultados das ciências e das técnicas e com os quais evitamos, consequentemente, a polissemia e a ambiguidade do léxico comum. Essa posição idealizada pressupõe que o conhecimento científico preexiste a qualquer expressão e é independente das línguas e culturas.

A partir dessa concepção, entende-se o conhecimento científico e técnico como universalmente uniforme; a estruturação consensual de todos os âmbitos da especialidade e a estruturação de uma área de domínio como única para a totalidade de grupos e contextos; o conhecimento científico como neutro e destituído de traço social, cultural ou ideológico; consenso no uso dos termos normatizados, além de considerar as características mais importantes por todos os grupos e contextos e representar pelo termo normatizado (Cabré, 1999).

Para Krieger (2001), a revisão a que os enfoques linguísticos submeteram a teoria e a aplicação terminológica normalizadora está situada na tensão de duas concepções antagônicas a respeito da constituição e da natureza das terminologias. A primeira nega a naturalidade dos termos ao sistema linguístico e, por isso, anula a dimensão comunicativa das terminologias, desconsiderando o fato de que os léxicos temáticos são importantes elementos constitutivos dos textos que veiculam conhecimentos especializados.

A recusa da naturalidade dos termos é fruto da crença de que há absoluto artificialismo nas terminologias, devido à forte 
presença de formantes gregos e latinos nas nomenclaturas das ciências taxionômicas como, por exemplo, a Zoologia, a Química etc. Coseriu (1986) reforça essa posição quando afirma que as terminologias estão fora da língua como sistemas de significação, portanto não pertencem à linguagem, visto que seu emprego objetiva apenas a classificação científica.

Em oposição a essa concepção, há a compreensão de que as terminologias são unidades lexicais; logo, são componentes naturais do sistema linguístico. O desenvolvimento do pensamento estrutural, o alargamento do conceito de ciência e de estudos linguísticos, sociológicos, antropológicos, psicanalíticos, especialmente lacanianos, ampliaram os campos de saber, alcançando estatuto científico. Com isso, as áreas humanas do conhecimento estabeleceram seus princípios epistemológicos e desenvolveram metodologias próprias. As terminologias diferenciaram-se daquelas de natureza taxionômica, anteriormente citadas, e muitas vezes se confundiram com o léxico comum das linguas. Tal movimento, afirma Krieger (2001), fez com que os termos revelassem, de várias formas, sua naturalidade em relação aos sistemas linguísticos, começando pela consonância aos padrões morfossintáticos das línguas que o veiculam, fossem eles originais ou produto de estruturas neológicas.

Muitos estudos, portanto, contribuíram para o redimensionamento das práticas terminológicas, envolvendo questões filosóficas, tradutológicas, sociolinguísticas, entre outras, pois apontaram deficiências da TGT para explicar o funcionamento do léxico temático e colaboraram para o avanço dos estudos terminológicos clássicos, com atenção aos aspectos linguísticos e pragmáticos dos termos. Ou seja, uma teoria terminológica que enfocasse os aspectos comunicativos da linguagem em detrimento de questões normalizadoras.

Tal constatação não nega, contudo, a importância e contribuição da TGT para a consolidação desse campo do conhecimento e a constituição de uma identidade própria, independente da lexicografia e da lexicologia. Mas ajuda a compreender porque a TGT, concepção tradicional da terminologia com excessiva normalização da disciplina em nome da universalidade dos seus princípios, abre espaço à Teoria Comunicativa da Ter-

TradTerm, 16, 2010, p. 343-364 
minologia (TCT), uma teoria mais abrangente e flexivel, cujo instrumental teórico-metodológico procura explicitar, com mais clareza, os fenômenos que envolvem a comunicação especializada, descrevendo os termos, suas unidades mais representativas, sua complexidade, além de contemplar a variação linguística em toda a sua dimensão.

\section{Teoria Comunicativa da Terminologia (TCT): paradigma terminológico}

Maria Teresa Cabré e seu grupo de colaboradores, da Universidade de Pompeu Fabra, em Barcelona, estabeleceram os paradigmas terminológicos da TCT em sua obra de 1999, embora a autora já discutisse diferentes possibilidades de abordagem para a Terminologia em sua obra de 1993, bem como em conferências, seminários e cursos.

A proposta estabelecida por Cabré (1999) e discutida em Cabré et al. (1998) está ancorada em pilares teóricos que fundamentam esse modelo e integra a função representacional à comunicativa. Atenta aos diferentes niveis de formalidade e de dominios especializados e estruturalmente diversos, a proposta introduz as bases de uma teoria que integra a dimensão linguística das terminologias, aberta à multiplicidade de aplicações da disciplina:

A teoría que propomos pretende dar conta dos termos como unidades singulares e, em algumas vezes, similares a outras unidades de comunicação, dentro de um sistema global de representação da realidade, admitindo a variação conceitual e denominativa, considerando a dimensão textual e discursiva dos termos. ${ }^{5}$ (Cabré, 2000:120, tradução nossa)

5 "La teoria que proponemos pretende dar cuenta de los términos como unidades singulares y a La vez similares a otras unidades de comunicación, dentro de um esquema global de représentación de la realidad, admitiendo La variación conceptual y denominativa, y teniendo em cuenta la dimensión textual y discursiva de los términos." 
Na TCT, a UT é uma unidade léxica, composta de forma ou denominação; seu conteúdo pode variar de acordo com a seleção de traços em situação pragmática comunicativa, portanto não pode ser reduzida a um conceito independente de sua forma, nem a uma denominação separada do conteúdo. É uma unidade descrita como denominativo-conceitual, dotada de capacidade referencial, que pode exercer funções distintas (referencial, expressiva, conativa etc.) com possibilidade para ser termo ou palavra, de acordo com o contexto e a situação de uso. Essa potencialidade decorre da seleção de traços morfossintáticos, semânticos e pragmáticos específicos.

Isso é possivel, porque o termo pertence ao sistema linguístico; consequentemente, as regras gerais que regem o funcionamento do léxico são as mesmas que o regulamentam. Desse modo, as possiveis diferenças entre termos e palavras se anulam, esclarece Cabré et al. (1998), visto que não existe um conjunto de termos isolados constituindo uma língua periférica à língua geral, mas sim signos da língua natural, que se realizam em determinadas situações como palavras e, em outras, como termos. A especialização ou não de um conceito é estabelecida por critérios temáticos ou pragmáticos, já que os conceitos não têm um modo de funcionamento distinto dos significados da língua geral e também podem apresentar graus de especialização.

Nessa perspectiva, a variação é entendida como fenômeno natural, inerente à linguagem, pois os conceitos também estão sujeitos às influências de fatores externos, como os socioculturais e linguísticos de uma comunidade como, por exemplo, os dispositivos midiáticos por onde eles circulam e se difundem. Assim, a variação passa a ser considerada e deve estar adequadamente descrita na terminologia.

Baseada nesses aspectos, a TCT se estrutura nos seguintes parâmetros (Cabré, 1999:100-103):

a) é um campo interdisciplinar, ancorado na teoria do conhecimento, responsável por explicar como se conceitualiza a realidade, os tipos de conceitualização que podem acontecer e a relação dos conceitos entre si e com suas possíveis denominações; a teoria da comunicação que descreve as situações em que a co-

TradTerm, 16, 2010, p. 343-364 
municação pode se dar; e a teoria da linguagem, que trata das unidades terminológicas propriamente ditas;

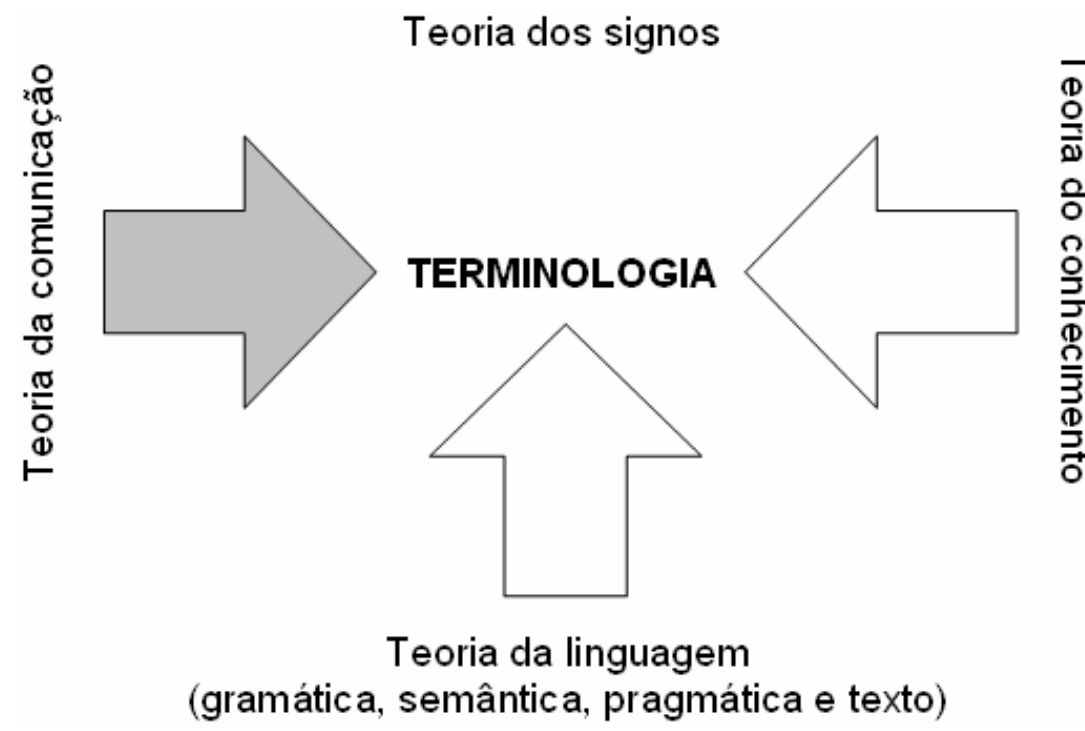

Figura 1: Teorias em que se fundamenta a TCT

b) os termos são unidades léxicas, singularmente ativadas por condições pragmáticas de adequação a um tipo de comunicação. A forma compartilha as características gerais da unidade; o conteúdo se singulariza pela seleção de traços adequados a cada tipo de situação, de acordo com o âmbito, o tema, a abordagem do tema, o tipo de texto, o emissor, o destinatário e a situação de comunicação;

c) os termos são unidades de forma e conteúdo, de tal modo que o conteúdo é simultâneo à forma. O conteúdo de um termo nunca é absoluto, mas relativo, de acordo com o âmbito e a situação de uso;

d) os conceitos de um mesmo âmbito especializado mantêm entre si relações de diferente tipo. O conjunto dessas relações entre os conceitos constitui a estrutura conceitual de uma matéria;

e) o valor do termo se estabelece a partir do lugar que ocupa na estruturação conceitual de uma matéria de acordo com os crité- 
rios estabelecidos no trabalho. Um conceito pode participar de mais de uma estrutura com valor igual ou diferente. Os termos não pertencem a um âmbito, porém são usados num âmbito com valor singularmente específico;

f) o objetivo da terminologia teórica é descrever forma, semântica e funcionalmente as unidades que podem adquirir valor terminológico, dando conta de como se ativam e explicando suas relações com outros tipos de signos do sistema. A terminologia aplicada visa à recompilação das unidades de valor terminológico num tema e situação determinada, estabelecendo suas características de acordo com essa situação;

g) a finalidade aplicada da recomplição e análise das unidades de valor terminológico usadas num âmbito é bastante diversa e permite muitas aplicações. Em todas se ativa a dupla função dos termos - a representação do conhecimento especializado e sua transferência, ainda que em graus e modos distintos e em situações também diversas.

A TCT extrapola o texto e o conhecimento especializado, propondo um estudo sob a perspectiva social, cognitiva e linguística. Cabré evidencia esse posicionamento quando afirma que

Tanto o conhecimento especializado, quanto os textos especializados, como as unidades terminológicas podem ocorrer em diferentes niveis de especialização e serem descritas em diferentes níveis de representação. Só assim, a terminologia do desejo passa a ser a terminologia da realidade. (Cabré, 1999:126)

O aspecto social, portanto, envolverá as características que um trabalho terminológico eficiente deve observar, ciente dos fins a que se propõe. Para isso é preciso adequá-lo às necessidades comunicativas dos profissionais e dos usuários em geral.

A perspectiva cognitiva se refere ao conhecimento do domínio especializado que será objeto do trabalho, visto que sem o conhecimento das especificidades da área-objeto não é possível localizar/identificar e estruturar sua terminologia. Por fim, a perspectiva linguística diz respeito ao uso de um modelo que abranja a competência e a atuação.

TradTerm, 16, 2010, p. 343-364 
Como disciplina linguística, a Terminologia, conforme Cabré (1999), busca descrever os códigos e os atos comunicativos especializados reais, explicar o funcionamento da terminologia dentro da linguagem natural, além de elaborar aplicações terminológicas diferentes que satisfazem necessidades comunicativas também diferentes.

Enfim, a TCT estabelece fundamentos mais amplos e flexíveis para a Terminologia, instrumentalizando e fortalecendo-a para o desenvolvimento de seu objetivo - estudar e descrever completa e adequadamente os objetos terminológicos, abrindo possibilidades para o tratamento de realidades distintas.

\section{Considerações Finais}

A dinamicidade do falante e das situações sociais se reflete na linguagem e exige a observação da diversidade inerente aos registros de linguagem, o que inclui as comunicações especializadas. Os estudos terminológicos têm proporcionado, à luz de teorias e práticas terminológicas, ideias novas, que complementam as já existentes e, em alguns momentos, se contrapõem a elas.

A TCT não é apenas uma ampliação da TGT, mas uma teoria que integra, teórica e metodologicamente, a variação linguística, tanto nos aspectos formais como conceituais. Para tanto, a TCT assume que os termos estão associados a características gramaticais - em todos os niveis de representação - e pragmáticas, inclusive a variação por critérios dialetais e funcionais distintos como os geográficos, históricos, sociais, temáticos, de nível de formalidade, de grau de especialização etc. É uma teoria que busca dar conta dos termos como unidades, ao mesmo tempo singulares e similares a outras unidades de comunicação, admitindo a variação conceitual e denominativa e levando em conta a dimensão textual e discursiva dos termos. Os diferentes princípios epistemológicos entre a TGT e a TCT demonstram que os novos rumos dos estudos terminológicos não podem ser compreendidos apenas como um alargamento dos objetos e do restrito alcance explicativo que constituem a TGT. Nessa perspectiva, a diferenciação entre domínio e discurso, como contextos de investigação, consiste no cerne das controvérsias. 
A breve revisão dessas correntes teóricas põe em relevo a importância de se aprofundar as pesquisas sobre os princípios de reconhecimento das unidades lexicais terminológicas, visto que os parâmetros clássicos tornaram-se insuficientes frente à diversidade terminológica da contemporaneidade e dos contextos culturais, científicos e tecnológicos. Evidencia também que a Terminologia, em virtude da dinamicidade do conhecimento e da constante divulgação nos meios de comunicação, é uma necessidade, uma prática, um recurso para aplicação e um campo do conhecimento.

\section{Referências Bibliográficas}

ALMEIDA, G. M. B. (2003) O percurso da terminologia: de atividade prática à consolidação de uma disciplina autônoma. TradTerm. São Paulo: Humanitas, n. 9, pp. 211-222.

BENVEnISTE, É. (1989) Problemas de linguística geral II. Campinas: Pontes.

CABRÉ, M. T. (2000) Sur la représentation mentale dês concepts: bases pour une tentative de modélisation. Le sens em Terminologie. Presses Universitaires de Lyon.

(1999) La terminologia: representación y comunicación: elementos para uma teoria de base comunicativa y otros artículos. Barcelona: Universitat Pompeu Fabra.

(1998) Elementos para uma una teoria de la terminologia: de la denominación a la comunicación. Atas do VI Simpósio Iberoamericano de Terminologia. Cuba.

(1993) La Terminología - teoría, metodología, aplicaciones ( ). Barcelona: Editorial Antártida/ Empúries. Trad. Castelhana de Carles Tebé.

CABRÉ, M. T. (1992) Sobre La diversidad y La terminologia. Actas Del III simpósio iberoamericano de terminologia. Barcelona: Servei de Llengua Catalana, Univeritat de Barcelona; Institut Universitari de Linguística Aplicada, Universitat Pompeu Fabra; CINDOC, pp. 363-377.

(1998) Elementos para uma teoria de La terminologia: hacia um paradigma alternativo. El lenguaraz. Revista acadêmica del Colégio de Traductores Públicos de La ciudad de Buenos Aires. 1/ 1, pp. 59-78.

TradTerm, 16, 2010, p. 343-364 
CABRÉ, M. T. et al. (1998) La terminologia hoy: replanteamiento o diversificación. Organon, vol. 12, n. 26, pp. 33-41.

COSERIU, E. (1986) Princípios de semântica estrutural. Madrid: Gredos. FELBER, H. (1996) En memória d'E. Wüster In: CABRÉ, M.T. Terminologia: selecció de textos d'E. Wüster. Barcelona: Servei de Llengua Catalana, Universitat de Barcelona, pp. 17-29.

GAUDIN, F. (1995) Terminologie: l'ombre du concept. Meta. Montreal, vol. 41, n. 4, pp. 605-621.

GAUDIN, F. (1991) Terminologie et travail scientifique: mouvement dês signes, mouvement des connaissances. Cahiers de linguistique sociale, 18, pp. 111-132.

(1995) Champs, clôutures et domaines: dês langues de spécialité à la culture scientifiqu. Meta, 40/2, pp. 229-237.

KRIEGER, M. G. (2001) Terminologia revisitada. In: KRIEGER, M. G.; MACIEL, A. M. B. (Orgs.) Temas de terminologia. Porto Alegre\&São Paulo: Ed. Universidade UFRGS\& Humanitas/USP.

LURQUIN, G. (1979) In Memoriam Eugen Wüster. Le langage et lhomme. Bruxelles, n. 40, pp. 55-71.

PAVEL, S.; NOLET, D. (2002) Manual de terminologia. Ministério de Obras Públicas e Serviços Governamentais do Canadá, catálogo $n^{\circ}$ S53-28.

PLATÃO (2001) Crátilo. Lisboa: Instituto Piaget.

POTTIER, B. (1992) Théorie et analyse em linguistique. Paris: Hachette, 2a. $2^{\text {a }}$ ed.

REY, A. (1979) La terminologie: noms et notions. Paris: Paris Universitaires de France.

RONDEAU, G. (1984) Introduction à la terminologie. Québec: Gaëtan Morin.

SAGER, J. C. (1990) A practical course in terminology processing. Amsteram: John Benjamins.

SAUSSURE, F. de (1994) Cours de linguistique générale. (Édition critique préparée par Tullio Mauro). Paris: Payot.

SIDARUS, A.-Y (1990) Onomástica Aegyptiaca: La tradition des lexiques thématiques em Egypte a travers lês ages et lês langues. HistoireEpistemologie-Language, s. 1., 12 (1), pp. 7-19.

TEMMERMAN, R. (1997) Questioning the univocity ideal. The difference between sociocognitive Terminology and traditional Terminology. Herms. Journal of linguistics 18, pp. 51-91. 
364

VYGOTSKY, L. S. (1977) Thought and language. Cambridge, MS: MIT Press.

WÜSTER, E. (1998) Introducción a la teoria general de la terminologia y a la lexicografia terminológica. Barcelona: Universitat Pompeu Fabra.

TradTerm, 16, 2010, p. 343-364 